\title{
Gestão da Imagem: Desenvolvendo um Instrumento para a Configuração da Imagem de Produto
}

\author{
Deonir De Toni \\ Maria Schuler
}

\section{RESUMO}

A imagem que o consumidor tem de um produto influencia fortemente sua decisão de compra. É através dessa imagem que ele vai pensar no produto, durante seu processo de decisão. Conhecer detalhadamente a imagem que determinado público desenvolve de um produto é uma ambição dos pesquisadores de Marketing. Essa pesquisa valida um dos procedimentos visando à geração de um instrumento poderoso e de fácil aplicação para configurar a imagem de produtos (TCIP - Técnica de Configuração da Imagem de Produtos). Primeiro foram identificadas e organizadas as principais idéias que formam a imagem do Telefone Celular para um grupo de estudantes universitários. Depois testou-se a validade do procedimento adotado. O procedimento mostrou-se válido e confiável.

Palavras-chave: imagem; imagem de produto; imagem de marketing.

\begin{abstract}
The image consumers develop regarding a certain product influences their purchasing decision. It's through this image they will think about the product, during the purchasing decision process. To know in details the image certain public develops about a product is a Marketing researcher's ambition. This research validates a procedure regarding the generation of a powerful image configuration tool that is very easy to apply. To test the Products Image Configuration Technique - PICT, first the main ideas composing the Cellular Telephone image for a college students group were identified and organized. Than the adopted procedure's validity was tested. The procedure showed to be valid and reliable.
\end{abstract}

Key words: image; products image; marketing image. 


\section{INTRODUÇÃO}

Um dos principais instrumentos do pensamento humano são as imagens mentais, através das quais se representa o mundo, para poder refletir sobre os seus objetos, mesmo que eles não estejam presentes. As imagens constituem um dos materiais intelectuais mais importantes do homem, sendo capazes de influenciar e direcionar o seu comportamento. A compreensão da imagem que o consumidor forma de um determinado produto constitui importante trunfo para um melhor direcionamento das decisões sobre lançamento, aperfeiçoamento e desenvolvimento de estratégias de posicionamento de produtos, bem como do composto de comunicação para melhor apoiar seu desempenho no mercado.

Comentando o estado de desenvolvimento da Teoria da Imagem em Marketing, Parameswaran e Pisharodi (1994) indicam que, em função da variedade de definições e de técnicas de mensuração, muitos progressos necessitam ser feitos antes de efetivar-se tal teoria.

Reconhecendo a importância da imagem que o consumidor faz do produto no processo de decisão de compra, a questão que norteou este trabalho é: Como determinar a Imagem Central de um produto?

Na primeira parte do trabalho expõem-se os principais conceitos de imagem e a forma como ela pode ser organizada e recuperada na memória. Na segunda parte apresenta-se o método de pesquisa proposto (TCIP - Técnica de Configuração da Imagem de Produtos). Na terceira parte apresenta-se a comparação entre os resultados obtidos com a aplicação do procedimento proposto e com outros procedimentos já validados. No final, são apresentadas algumas conclusões.

\section{ReVISÃo dA Literatura}

\section{O Conceito de Imagem}

Numa perspectiva mercadológica, Barich e Kotler (1991) apresentam quatro tipos de imagem: a da marca (como as pessoas percebem marca particular em relação às suas concorrentes); a dos produtos (como as pessoas vêem determinada categoria de produtos); a de marketing (a forma como é vista a 
qualidade da oferta e mix de marketing da organização) e a imagem corporativa (como as pessoas percebem a empresa como um todo). Já Stern, Zinkhan e Jaju (2001) confirmam três diferentes, mas relacionados tipos de imagens: imagens da marca e/ou produto; imagem da corporação; e imagem do estabelecimento comercial.

Dobni e Zinkhan (1990) e Stern et al. (2001) fazem importante revisão dos diferentes conceitos de imagem de produto ou marca nos últimos trinta anos e concluem que a imagem é o resultado das impressões que o consumidor recebe de muitas fontes. Essa definição genérica trata a imagem do produto como ampla abstração, enfatizando tanto a percepção do consumidor quanto a divergência entre a percepção e a realidade. Ressaltam ainda que as pessoas compram objetos não somente pelo que eles podem fazer, mas também pelo que eles significam. As coisas que as pessoas compram têm um significado pessoal e social, além de suas funções utilitárias. Segundo Levy (1981), os atributos simbólicos são tão importantes quanto os atributos funcionais. Os produtos, segundo a visão desses autores, apresentam uma imagem de personalidade (personality image), assim como as pessoas. Essa personalidade não é determinada somente por características físicas do produto, mas também por um conjunto de outros fatores, tais como a propaganda, o preço e outras associações psicológicas. É preciso ainda considerar que a imagem é uma interpretação das informações recebidas, um conjunto de inferências e reações sobre o produto. Assim, sua formação não depende apenas das mensagens racionalmente emitidas, na estratégia de comunicação do produto, mas também da forma como o consumidor vai recriar o significado das mensagens que recebe.

As imagens de produto são um conjunto de idéias, sentimentos e atitudes que o consumidor tem sobre o produto. Na perspectiva cognitiva, a imagem é tratada como entidade externa e construção mental, que inclui idéias, sentimentos, atitudes, conceitos mentais, entendimento e expectativa.

As cinco classificações de imagem de marca/produto feitas por Stern et al. (2001) revelam dois pontos comuns. O primeiro é que a imagem se apresenta como constructo gestalt, ou seja, um todo organizado e estruturado. O segundo é o processo de transação entre os estímulos da comunicação e a percepção do consumidor. Assim, imagem é o que as pessoas pensam e sentem sobre o produto ou marca, sendo condicionada pela natureza do objeto, bem como pela natureza do observador (Stern et al., 2001).

Reynolds e Gutman (1984) identificam imagem como um conjunto de significados hierarquicamente organizados e armazenados na memória, cuja identificação se dá a partir da rede de relacionamentos entre esses significados. 
Assim, o conceito de imagem congrega sensações, emoções, percepções, conceitos, sentimentos, informações, idéias, ideais, impressões, suposições e expectativas, sendo que a constituição de uma imagem depende da forma específica pela qual um indivíduo ou grupo trata as informações objetivas colhidas do contato com o objeto da imagem (Dobni \& Zinkhan, 1990; Poiesz, 1989; Stern et al., 2001).

A partir da revisão de diferentes conceitos de imagem sob a perspectiva do Marketing (Dobni \& Zinkhan, 1990; Poiesz, 1989; Reynolds \& Gutman, 1984; Stern et al., 2001) e da Psicologia (Gentner, 1983; Moscovici, 2000), este trabalho propõe que o conceito de imagem mercadológica pode ser sumariado da seguinte forma: Imagens são representações, impressões, convicções e redes de significados de um objeto (produto/marca, corporação, loja) armazenado na memória de forma holística.

O trabalho parte do pressuposto de que a imagem se constitui de muitas dimensões, algumas tangíveis, algumas intangíveis; algumas mensuráveis, outras não mensuráveis; algumas significantes, outras insignificantes; algumas mutáveis, outras imutáveis. Assim, a imagem combina um conjunto de fatores tangíveis (funcionais) e intangíveis (cognitivos, simbólicos e emocionais) (Lindquist, 1975). Desse modo, pode-se supor que: Imagem de produto é uma construção sistêmica, podendo ser configurada a partir de um sortimento de elementos funcionais, simbólicos, cognitivos e emocionais (ver Figura 1).

\section{Figura 1: Principais Elementos que Configuram as Imagens de Produto}

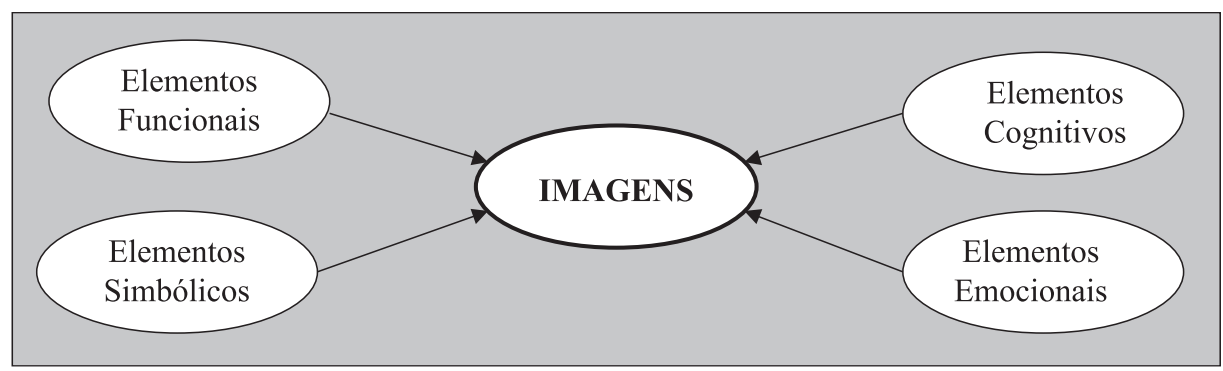

Fonte: Lindquist (1975); Levy (1981); Goleman (1995); Ledoux (2001); Stern et al. (2001).

Os elementos funcionais são traduzidos a partir de uma série de características físicas, como tamanho, design, cor, cheiro, valor etc. que expressam a utilidade do produto (Stern et al., 2001).

Como elementos simbólicos, os produtos são avaliados também pelo que eles significam ou representam para o indivíduo (Levy, 1981; Martineau, 1958). 
Os elementos cognitivos são construções mentais sobre o objeto, sendo que o indivíduo avalia a imagem do produto como uma impressão e um conjunto de atitudes e percepções sobre o objeto (Dichter, 1985; Martineau, 1958).

Os elementos emocionais revelam o conjunto de sentimentos (prazer, dor, alegria, medo etc.) que o indivíduo carrega em relação ao produto (Goleman, 1995; Ledoux, 2001; Reynold \& Gutman, 1984).

Supõe-se também que quanto mais importante um produto for para o indivíduo (envolvimento), maior tenderá a ser a rede de significados associada a ele.

\section{Organização e Recuperação das Imagens na Memória}

Há muitas formas de compreender como as imagens estão organizadas no sistema cognitivo e na memória do indivíduo. Duas abordagens importantes para essa compreensão são a Teoria dos Esquemas (Análise de Conexidade) e a Teoria do Núcleo Central.

A Teoria dos Esquemas indica como os conceitos estão organizados na mente. Esquemas são estruturas mentais para organizar significativamente vários conceitos inter-relacionados, com base em experiências anteriores (Fiske \& Taylor como citado em Ayrosa, 2002; Sternberg, 2000). São estruturas de conhecimento que auxiliam a entender a interação da estrutura da memória permanente e os atuais estímulos. Dentre as várias funções dos esquemas, estão a de codificar os estímulos, categorizar as informações entrantes e reduzir o processamento das informações. Além disso, os esquemas afetam fortemente o processo de julgamento sobre determinados objetos ou fenômenos (Meyers-Levy \& Tybout, 1989).

Em paralelo à Teoria dos Esquemas, há a abordagem que trata das conexões entre os elementos de uma imagem e entre os dados contidos na memória humana. Esta estrutura cognitiva ajuda a reconhecer um objeto, quando ele é percebido, e a trazer para a memória de trabalho grande parte das informações que se tem sobre ele (Akhter, Andrews, \& Durvasula, 1994).

A Teoria do Núcleo Central identifica que o homem organiza as informações de forma dinâmica e evolutiva, dispondo-as em torno de um Núcleo Central e de um conjunto de elementos periféricos (Abric, 1984, 1993; Sá, 1996). Segundo o pesquisador francês Jean-Claude Abric (1984) o Núcleo Central é "constituído de um ou de alguns elementos que dão à representação o seu significado e que ocupam, na estrutura da representação, uma posição privilegiada" (p. 170). Dessa forma, o Núcleo Central constitui um subconjunto da representação, composto de um ou de alguns elementos cuja ausência desestruturaria a representação, ou lhe daria uma significação completamente diferente (Sá, 1996). Os atributos que 
compõem o Núcleo Central são marcados pela memória coletiva, são estáveis, resistentes à mudança e sua função é gerar significação para as imagens. Em torno do sistema central da imagem há o sistema periférico, constituído pelos atributos mais flexíveis, sensíveis ao contexto imediato. Sua função é permitir a adaptação à realidade atual, bem como a diferenciação do conteúdo e a proteção ao sistema central. Assim, os sistemas periféricos estão mais próximos das práticas do cotidiano e mais sujeitos às mudanças (Sá, 1996).

Tendo em vista a geração de um método para a configuração da imagem de produtos, torna-se, dessa forma, muito importante a delimitação de seu Núcleo Central. No entanto, pensando em utilizar para isso procedimentos quantitativos e confiáveis, a adoção pura e simples do conceito de Núcleo Central de Abric pesa como decisão, pois nem toda a imagem tem um Núcleo Central, e a determinação de se ela o tem ou não implicaria, metodologicamente, uma fase qualitativa prévia bem complexa e exigente. Sendo assim, para o desenvolvimento e teste do procedimento aqui defendido, substituiu-se o conceito de Núcleo Central de Abric pelo de Imagem Central. A Imagem Central é ainda o sistema central da imagem, mas não é mais considerada como determinante para o reconhecimento do objeto da imagem, como é o caso do Núcleo Central de Abric. Para efeito desse trabalho, parte-se do pressuposto de que os atributos pertencentes à Imagem Central são os que apresentam a maior probabilidade de gerar o reconhecimento do objeto da imagem, quando evocados.

Em relação à recuperação das imagens na memória humana, Schacter (1996) afirma que o sistema de memória é construído de tal forma que é mais provável que o indivíduo se lembre do que é mais importante para ele. Assim, o sujeito lembra com mais facilidade quando o material codificado ou aprendido possui associação com algo conhecido, com algo que tenha sentido para ele, ou com algo que tenha sido produzido pela excitação emocional (Ledoux, 2001; Lockhart, 2001; Logie \& Sala, 2001). Dados fortemente ligados à intensidade emocional podem facilmente vir à tona de forma espontânea (Schacter, 1996; Sternberg, 2000).

\section{Método de Pesquisa}

A partir da questão de pesquisa: Como determinar a Imagem Central de um produto? buscou-se gerar e validar um procedimento metodológico confiável para tal.

Utilizou-se, para testar o procedimento, o produto Telefone Celular, pela sua familiaridade junto ao universo da amostra, e pela possibilidade de comparação entre os resultados do estudo atual com os de um estudo anterior, junto a amostra 
similar, da mesma região geográfica, realizado por Kraft e Nique (2002) a partir da técnica ZMET (Zaltman Metaphor Elicitation Technique).

O público alvo é de estudantes de Administração de uma Faculdade do Rio Grande do Sul. As entrevistas foram realizadas nos meses de novembro e dezembro de 2003, março e abril de 2004, sendo que para a primeira etapa o número de respondentes foi de 100 estudantes e para a segunda de 31 estudantes.

Essa pesquisa foi realizada em duas etapas. A primeira buscou identificar e organizar os atributos funcionais, simbólicos cognitivos e emocionais que compõem a imagem do Telefone Celular para a amostra pesquisada, segundo o procedimento indicado pela TCIP. A segunda etapa procurou validar o procedimento indicado pela TCIP para essa finalidade.

\section{Identificação e Organização da Imagem do Produto, segundo a TCIP}

Para abordar a amostra acima descrita, foi escolhido um estímulo a ser apresentado aos respondentes (Termo Indutor), para que eles manifestassem as idéias por ele suscitadas (atributos da imagem). O Termo Indutor utilizado foi a expressão "Telefone Celular", verbalmente pronunciada. As questões utilizadas para verificar o que esse produto lembra aos respondentes constam do Quadro 1, abaixo.

\section{Quadro 1: Questões da Entrevista Estruturada}

\begin{tabular}{|l|l|}
\hline \multicolumn{1}{|c|}{$\begin{array}{c}\text { Elementos de } \\
\text { identificação }\end{array}$} & \multicolumn{1}{c|}{ Questões } \\
\hline $\begin{array}{l}\text { Funcional, cognitivo, } \\
\text { emocional e } \\
\text { simbólico }\end{array}$ & $\begin{array}{l}\text { 1. Quando eu digo TELEFONE CELULAR, qual a primeira coisa que lhe vem à } \\
\text { cabeça? }\end{array}$ \\
\cline { 2 - 2 } Cognitivo & 2. Que outras idéias lhe vêm à mente sobre o TELEFONE CELULAR? \\
\hline Simbólico & 4. Qual o significado que o TELEFONE CELULAR tem para você? \\
\hline Emocional & $\begin{array}{l}\text { 5. Quais os sentimentos que lhe vêm à mente, quando eu digo o TELEFONE } \\
\text { CELULAR? }\end{array}$ \\
\hline Funcional & 6. Quais os benefícios que o TELEFONE CELULAR traz para você ? \\
\hline
\end{tabular}

Fonte: Formulação dos Autores.

De acordo com a frequiência e com a ordem de citação dos atributos, foram-lhes designadas posições de proximidade maior ou menor com o Termo Indutor, configurando-se assim as zonas chamadas de Imagem Central e Imagem Periférica.

A coleta de dados foi realizada pelo pesquisador, a partir de um roteiro de questões abertas, com a técnica de associação livre (ver Quadro 1).

Utilizou-se então a análise de conteúdo, sobre as respostas dos participantes da 
pesquisa, para a identificação dos atributos constituintes da imagem do produto analisado. Os atributos gerados sofreram um primeiro tratamento em que foram levantadas sua frequiência e ordem de aparição. Esse tratamento foi proposto inicialmente por Abric (1984) e Vergès (1992) e visa criar uma distinção entre os atributos mais próximos e os mais distantes do Termo Indutor. Os mais próximos serão considerados como pertencentes à Imagem Central e os mais distantes serão localizados na Periferia da Imagem.

O Quadro 2, no capítulo reservado à apresentação dos resultados, além dos atributos da imagem do Telefone Celular para essa amostra, traz o Valor de Freqüência (VF), o Valor de Ordem (VO) e o Valor Total (VT) de cada atributo. O Valor de Frequiência é o número de vezes que o atributo foi citado pelos respondentes. Para atribuir um Valor de Ordem, o atributo citado em primeiro lugar recebe valor 5, o que foi citado em segundo lugar recebe valor 4, e assim por diante até o quinto atributo citado que recebe valor 1. Após o quinto citado, os atributos não mais recebem Valor de Ordem $(\mathrm{VO}=0)$, apenas o Valor de Frequiência. O Valor Total é um somatório simples do Valor de Ordem com o Valor de Frequiência. Os atributos que se destacam por alta Freqüência de Citação (VF) e alto Valor de Ordem (VF), então com alto Valor Total (VT), são considerados como candidatos a comporem a Imagem Central do produto testado.

Para gerar diferentes áreas de proximidade com o estímulo dado para evocar a imagem do produto junto à amostra (Termo Indutor), aplicou-se a divisão por quartis (MICROSOFT EXCEL) ao conjunto de Valores Totais encontrados. Dessa forma foi possível identificar quatro grupos de atributos, considerando-se a Periferia da Imagem como composta pelo primeiro quartil (VT=5 a 33), a Segunda Periferia da Imagem como formada pelo quartil que abriga os atributos com VT= $(34 \mathrm{a}$ 63), a Primeira Periferia como representada pelo terceiro quartil (VT=64 a 154) e a Imagem Central do produto como sendo o conjunto de atributos com maior Valor Total (VT=155 a 217).

\section{Validação do Procedimento Recomendado pela TCIP para a Identificação e Organização da Imagem do Produto}

Para validar o procedimento utilizado pela TCIP para distinguir entre os atributos que fazem parte da Imagem Central e os que fazem parte da Periferia da Imagem, os seus resultados foram primeiramente comparados aos de dois outros procedimentos, que cumprem a mesma finalidade, utilizados normalmente por outros pesquisadores.

O primeiro trata-se de um software (EVOC) utilizado na Psicologia Social para configurar as representações mentais dos indivíduos. O segundo é o ZMET 
(Zaltman Metaphor Elicitation Technique), utilizado numa pesquisa anterior, realizada por Kraft e Nique (2002), também para configurar a imagem que os consumidores têm do Telefone Celular.

\section{Organização dos Atributos da Imagem, segundo o EVOC}

OEVOC foi desenvolvido na França por Pierre Vergès (1992) e seus colaboradores e, a partir da combinação da frequiência de citação e da ordem média de citação de cada atributo, busca identificar quais apresentam maior probabilidade de pertencerem ao Núcleo Central e ao Sistema Periférico das imagens. Para traçar a comparação com o EVOC, foi utilizado o mesmo banco de dados coletados a partir do instrumento proposto. Os critérios estabelecidos pelo EVOC, para a delimitação do sistema central e periférico das imagens, são: a) Núcleo Central: atributos com Valor de Ordem (VO) menor que a média das médias das citações, ou Valor de Ordem Médio (VOM), e VF maior ou igual que o Valor de Frequência Médio (VFM) das citações; b) Elementos Intermediários 1: atributos com VO maior ou igual à média das médias das citações (VOM), e VF maior ou igual que o VFM das citações; c) Elementos Intermediários 2: atributos com VO menor que a média das médias das citações (VOM), e VF menor que o VFM das citações; e d) Sistema Periférico: atributos com VO maior ou igual à média das médias das citações (VOM), e VF menor que o VFM das citações.

O Valor de Frequiência Médio (VFM) é calculado pelo total de frequiência de atributos citados, dividido pelo número de diferentes atributos (VFM do TC=686/ 25= 27) (Quadro 3).

O VO e o VOM são calculados a partir da atribuição de pesos aos atributos. Assim, o atributo citado em primeiro lugar recebe peso 1, quando for citado em segundo lugar peso 2 e assim sucessivamente até o último atributo citado. Por fim, em somatório simples, chega-se ao VO. Por exemplo, o atributo 'aparelho', foi citado 53 vezes, sendo 4 vezes em primeiro lugar, 5 em segundo, 17 em terceiro, 8 em quarto, 11 em quinto, 3 em sexto, 4 em sétimo e 1 vez em oitavo. Calculando $(4 \times 1)+(5 \times 2)+(17 \times 3)+(8 \times 4)+(11 \times 5)+(3 \times 6)+(4 \times 7)+(1 \times 8)$ obtém-se o Valor de Evocação $(\mathrm{VE})=206$ que, dividido pela frequiência (53), chega ao $\mathrm{VO}=3,887$. Já o Valor de Ordem Médio (VOM) corresponde à média das médias das citações e é calculado a partir da soma dos Valores de Evocação (VE) dividido pelo total de citações (VOM = 2933/686=4,3) (ver Quadro 4).

A partir do Valor de Frequiência Médio (VFM do TC $=27$ ) e do Valor de Ordem Médio das citações (VOM do TC = 4,3) são estabelecidos o Núcleo Central, Elementos Intermediários e Periféricos do TC. O Quadro 4, da apresentação dos resultados, traz os resultados deste processo. 


\section{Organização dos Atributos da Imagem, segundo a ZMET}

A ZMET (Zaltman Metaphor Elicitation Technique) é uma ferramenta de pesquisa desenvolvida por Zaltman e Coulter (1995) com abordagem mais qualitativa, desenhada para (1) verificar os modelos mentais que dirigem o pensamento e comportamento do consumidor e (2) caracterizar estes modelos, utilizando as metáforas do consumidor. Esta técnica busca captar as imagens visuais e sensoriais dos indivíduos com o propósito de obter informações mais completas sobre os consumidores e fornecer mecanismos, para que as empresas possam melhor comunicar com seus clientes e produzir propagandas mais criativas, com o propósito de despertar a atenção e atingir os modelos mentais coletivos (Zaltman \& Coulter, 1995).

Na ZMET, a caracterização dos modelos mentais dos indivíduos se dá através da compreensão de metáforas, ou seja, de comparações que os respondentes são convidados a fazer, tendo o produto em mente, pois estas representam os pensamentos e sentimentos que lhes ocorrem. A análise das metáforas as divide em três níveis: superficiais, temáticas e profundas (Zaltman \& Coulter, 1995).

As metáforas profundas estão em nível fundamental, elementar, básico, onde estão organizados os processos de percepção e os pensamentos dos indivíduos. São estruturas básicas que influenciam a análise e ação dos consumidores. Conceitualmente, as metáforas profundas podem apresentar muita relação com o núcleo central das representações, em Abric e com a imagem central da TCIP.

As metáforas temáticas indicam as perspectivas gerais ou estruturas de um objeto e constituem outra forma de entender os pensamentos e sentimentos dos consumidores. São ainda temas que se conectam às várias metáforas profundas. Conceitualmente, as metáforas temáticas podem corresponder ao papel dos elementos intermediários, na configuração das representações, para Abric, e ao papel da primeira e segunda periferia, na TCIP.

As metáforas superficiais estão muito relacionadas a expressões do cotidiano. São chamadas metáforas superficiais, porque expressam as afirmações diretas dos indivíduos e, por isso, estão alocadas na 'superfície do pensamento', sendo facilmente acessadas. Conceitualmente, as metáforas superficiais podem corresponder aos elementos periféricos, na configuração de Abric e aos atributos periféricos da TCIP.

Segundo Churchill (1979), um princípio fundamental da ciência é que qualquer constructo ou característica deve ser mensurável pelo menos por dois, e preferencialmente por diferentes métodos. Assim, a triangulação, ou o uso de diferentes métodos, é uma estratégia para a validação de um procedimento metodológico (Flick, 1992). 
Ainda como forma de verificar a confiabilidade do procedimento de distinção entre os atributos Centrais e Periféricos, realizou-se um experimento.

\section{A Confiabilidade do Procedimento Recomendado pela TCIP para a Identificação e Organização da Imagem do Produto.}

Esta etapa da pesquisa partiu do pressuposto de que os atributos pertencentes à Imagem Central são os que apresentam a maior probabilidade de gerar o reconhecimento do objeto da imagem, quando evocados. Na primeira etapa da pesquisa, os entrevistados eram convidados a responder o que lhes vinha à mente, quando o nome do produto lhes era apresentado. Nesta segunda etapa, fez-se o caminho inverso, ou seja, buscou-se identificar que produto vinha à mente, dos respondentes, quando expostos aos conjuntos de atributos que compõem os sistemas central e periférico da imagem do Telefone Celular, tal qual foi determinado pela aplicação da TCIP. Assim, cada respondente recebeu dois estímulos diferentes (cartões com um conjunto de atributos do Telefone Celular). O primeiro estímulo foi feito com os atributos da Imagem Periférica do TC e o segundo estímulo com os atributos da Imagem Central do TC (Quadro 6 da apresentação dos resultados). A partir dos atributos dispostos em cartões, os respondentes foram convidados a verbalizar o primeiro produto que lhes vinha à mente. A amostra foi composta no mesmo universo que a amostra das fases precedentes da pesquisa, mas por indivíduos que não participaram das fases anteriores. O Quadro 7 apresenta os resultados deste teste.

O método para esta etapa da pesquisa foi um desenho experimental realizado durante o mês de abril de 2004, com 31 estudantes (17 homens e 14 mulheres) de uma Faculdade do Rio Grande do Sul. Para este estudo, as variáveis independentes são os atributos que serviram de estímulo, e a variável dependente observada é o reconhecimento do produto. A partir da classificação dos estudos experimentais apresentados por Malhotra (2001), este trabalho enquadra-se como estudo pré-experimental, ou seja, não há o emprego de processos de aleatorização para controlar os fatores estranhos. Dentro de estudos préexperimentais, este trabalho se localiza como estudo de caso One-Shot, ou seja, é estudo cujo grupo de unidade de teste é exposto a um tratamento, sem a necessidade de ter grupo de controle.

A técnica de coleta de dados utilizada para este experimento foi a associação livre de idéias, realizada individualmente com cada participante. Os estímulos foram gerados a partir dos atributos dispostos em cartões, de forma aleatória; os entrevistados foram convidados a responder: "A partir destes atributos, qual o produto que lhe vem à mente?". As respostas de cada participante foram registradas e analisadas a partir da freqüência de citação e de sua representatividade. 


\section{Apresentação dos Resultados}

Os resultados desta pesquisa são apresentados em cinco etapas.

\section{Identificação e Ordenação dos Atributos da Imagem do Telefone Celular através da TCIP}

A análise do conteúdo das respostas dadas à entrevista estruturada (ver Quadro 1) encontrou 25 atributos que correspondem às idéias que estão associadas à idéia geral de Telefone Celular para essa amostra. Segundo o procedimento relatado no método, os atributos foram ordenados pela sua proximidade e força de ligação com a imagem do Telefone Celular, resultando na configuração de imagem disposta no Quadro 2, abaixo.

\section{Quadro 2: Identificação e Ordenação dos Atributos da Imagem do Telefone Celular através da TCIP}

\begin{tabular}{|c|c|c|c|c|}
\hline & ATRIBUTOS & VF & Vo & VT \\
\hline \multirow{8}{*}{$\begin{array}{l}\text { IMAGEM } \\
\text { CENTRAL }\end{array}$} & Praticidade & 66 & 151 & 217 \\
\hline & Agilidade:Rapidez, Fácil de Encontrar & 67 & 122 & 189 \\
\hline & Necessidade: Essencial, Indispensável & 56 & 116 & 172 \\
\hline & Aparelho: Instrumento, equipamento & 53 & 118 & 171 \\
\hline & Tecnologia: Moderno, Inovação & 47 & 118 & 165 \\
\hline & Utilidade & 49 & 112 & 161 \\
\hline & Comunicação & 44 & 111 & 155 \\
\hline & Facilidade de Comunicação: Facilita a Vida & 50 & 105 & 155 \\
\hline \multirow{5}{*}{$\begin{array}{l}\text { PRIMEIRA } \\
\text { PERIFERIA }\end{array}$} & Comodidade: Conforto & 40 & 84 & 124 \\
\hline & Chatice: Problemas & 18 & 52 & 70 \\
\hline & Trabalho: Ferramenta, Negócio & 28 & 40 & 68 \\
\hline & Conta : Custo, Preço. & 16 & 48 & 64 \\
\hline & Onipresença: Poder se comunicar em qualquer hora e lugar & 29 & 35 & 64 \\
\hline \multirow{6}{*}{$\begin{array}{c}\text { SEGUNDA } \\
\text { PERIFERIA }\end{array}$} & Marca & 10 & 49 & 59 \\
\hline & Interação: Contato com Pessoas, Compartilhar Momentos & 20 & 36 & 56 \\
\hline & Segurança: Emergência & 26 & 24 & 50 \\
\hline & Discrição: Fácil de Carregar, Compacto, Sofisticado & 14 & 31 & 45 \\
\hline & Serviço: Agenda, Recado, Despertador, Mensagem & 13 & 27 & 40 \\
\hline & Status & 9 & 25 & 34 \\
\hline \multirow{6}{*}{ PERIFERIA } & Informação & 5 & 17 & 22 \\
\hline & Prazer: Agradável, Satisfação & 8 & 7 & 15 \\
\hline & Solução: Resolver Problemas & 7 & 7 & 14 \\
\hline & Liberdade & 3 & 9 & 12 \\
\hline & Alegria & 4 & 3 & 7 \\
\hline & Companheirismo: Está sempre comigo & 4 & 1 & 5 \\
\hline
\end{tabular}

Fonte: Tratamento dos Dados. 
O Quadro 2 indica que os atributos: praticidade, agilidade, necessidade, aparelho, tecnologia, utilidade e facilidade de comunicação compõem a Imagem Central que a amostra tem com relação ao Telefone Celular. Estes atributos são mais estáveis e resistentes à mudança e sua função é dar significado ao Telefone Celular. Os atributos informação, prazer, solução, liberdade, alegria e companheirismo compõem a Imagem Periférica do Telefone Celular, para essa amostra. Estes elementos periféricos são mais flexíveis e sujeitos ao contexto imediato; a sua função é adaptar a imagem desse produto à realidade concreta.

O Quadro 3 indica, a partir da análise de conteúdo, como os atributos estão dispostos em relação às quatro categorias de atributos que compõem a imagem de produto.

\section{Quadro 3: Agrupamento dos Atributos do TC a partir de suas Categorias}

\begin{tabular}{|c|c|c|c|c|c|c|c|}
\hline Categoria & Atributos & VF & $\%$ & Categoria & Atributos & VF & $\%$ \\
\hline \multirow{10}{*}{ Funcionais } & Aparelho & 53 & 7,73 & \multirow{10}{*}{ Cognitivos } & Agilidade & 67 & 9,77 \\
\hline & Tecnologia & 47 & 6,85 & & Praticidade & 66 & 9,62 \\
\hline & Comunicação & 44 & 6,41 & & Necessidade & 56 & 8,16 \\
\hline & Conta & 16 & 2,33 & & Facilidade de Comunicação & 50 & 7,29 \\
\hline & Discrição & 14 & 2,04 & & Útil & 49 & 7,14 \\
\hline & Serviço & 13 & 1,90 & & Onipresença & 29 & 4,23 \\
\hline & Marca & 10 & 1,46 & & Trabalho & 28 & 4,08 \\
\hline & & & & & Solução & 7 & 1,02 \\
\hline & & & & & Informação & 5 & 0,73 \\
\hline & Subtotal & 197 & 28,72 & & Subtotal & 357 & 52,04 \\
\hline \multirow{6}{*}{ Simbólicos } & Interação & 20 & 2,92 & \multirow{6}{*}{ Emocionais } & Comodidade & 40 & 5,83 \\
\hline & Status & 9 & 1,31 & & Segurança & 26 & 3,79 \\
\hline & Companheiro & 4 & 0,58 & & Chatice & 18 & 2,62 \\
\hline & Liberdade & 3 & 0,44 & & Prazer & 8 & 1,17 \\
\hline & & & & & Alegria & 4 & 0,58 \\
\hline & Subtotal & 36 & 5,25 & & Subtotal & 96 & 13,99 \\
\hline Total & \multicolumn{5}{|c|}{$197+36+357+96$} & 686 & 100,00 \\
\hline
\end{tabular}

Fonte: Tratamento dos Dados.

Percebe-se que há, na imagem do TC, uma distribuição heterogênea entre os atributos funcionais $(28,72 \%)$, simbólicos $(5,25 \%)$, cognitivos $(52,04 \%)$ e emocionais $(13,99 \%)$, sendo que o desvio padrão é de 20,46 e a variância de 418,76. Há predominância dos atributos cognitivos (52\%) e funcionais (29\%), demonstrando que a imagem básica do TC, para o público pesquisado, é a de ser um produto mais funcional, com características de uso racional e prático. 


\section{Identificação e Ordenação dos Atributos da Imagem do Telefone Celular através do EVOC}

O tratamento do mesmo conjunto de dados através do EVOC resultou na organização dos atributos em diferentes áreas de proximidade com a idéia geral de Telefone Celular, como apresentado no Quadro 4, abaixo.

\section{Quadro 4: Identificação e Ordenação dos Atributos da Imagem do Telefone Celular através do EVOC}

\begin{tabular}{|c|c|c|c|c|c|}
\hline \multicolumn{3}{|c|}{ Núcleo Central } & \multicolumn{3}{|c|}{ Elementos Intermediários 1} \\
\hline \multicolumn{3}{|c|}{$\mathrm{VF} .>=27$ e $\mathrm{VO}<4,3$} & \multicolumn{3}{|c|}{$\mathrm{VF}>=27$ e $\mathrm{VO}>=4,3$} \\
\hline Atributos & VF & VO & Atributos & VF & VO \\
\hline Aparelho & 53 & 3,887 & Agilidade & 67 & 4,806 \\
\hline Comodidade & 40 & 4,225 & Onipresença & 29 & 5,517 \\
\hline Comunicação & 44 & 3,977 & Trabalho & 28 & 5,143 \\
\hline $\begin{array}{l}\text { Facilidade de } \\
\text { Comunicação }\end{array}$ & 50 & 4,286 & & & \\
\hline Necessidade & 56 & 4,286 & & & \\
\hline Praticidade & 66 & 4,030 & & & \\
\hline Tecnologia & 47 & 3,723 & & & \\
\hline Utilidade & 49 & 3,857 & & & \\
\hline \multicolumn{3}{|c|}{ Elementos Intermediários 2} & \multicolumn{3}{|c|}{ Sistema Periférico } \\
\hline \multicolumn{3}{|c|}{$\mathrm{VF}<27$ e $\mathrm{VO}<4,3$} & \multicolumn{3}{|c|}{$\mathrm{VF}<27$ e $\mathrm{VMO}>=4,3$} \\
\hline Atributos & VF & VO & Atributos & VF & VO \\
\hline Chatice & 18 & 3,222 & Alegria & 4 & 6,250 \\
\hline Conta & 16 & 3,125 & Companheiro & 4 & 7,000 \\
\hline Informação & 5 & 2,600 & Interação & 20 & 4,750 \\
\hline Liberdade & 3 & 3,667 & Prazer & 8 & 5,500 \\
\hline Marca & 10 & 1,100 & Segurança & 26 & 6,154 \\
\hline Discrição & 14 & 3,786 & Serviço & 13 & 4,308 \\
\hline Status & 9 & 3,222 & Solução & 7 & 5,714 \\
\hline
\end{tabular}

Fonte: Tratamento dos Dados.

\section{Identificação e Ordenação dos Atributos da Imagem do Telefone Celular através da ZMET}

O Quadro 5 apresenta os três níveis de metáforas, bem como seus respectivos construtos encontrados a partir da pesquisa da Kraft e Nique (2002), utilizando a ZMET. 


\section{Quadro 5: Identificação e Ordenação dos Atributos da Imagem do Telefone Celular através da ZMET}

\begin{tabular}{|c|c|c|}
\hline Metáforas & Construtos & Atributos (Kraft \& Nique, 2002) \\
\hline \multirow[b]{4}{*}{ Profundas } & Recurso & $\begin{array}{c}\text { Aparelho que traz economia de tempo, facilita a vida, } \\
\text { qualquer hora e lugar }\end{array}$ \\
\hline & Conexão & Conecta e aproxima as pessoas, relação entre as pessoas \\
\hline & Container & Segurança, instrumento de proteção, facilita a ligação \\
\hline & Transformação & Proporciona liberdade, comodidade, tranqüilidade, status, etc. \\
\hline \multirow{4}{*}{ Temáticas } & Segurança & Fonte de segurança e proteção \\
\hline & Companheiro & $\begin{array}{c}\text { Aproxima as pessoas, facilita novos relacionamentos, } \\
\text { minimiza a solidão }\end{array}$ \\
\hline & Libertador & Traz a sensação de liberdade \\
\hline & Tranqüilizador & $\begin{array}{l}\text { Facilita e agiliza os negócios, ferramenta de trabalho, traz } \\
\text { comodidade }\end{array}$ \\
\hline \multirow{3}{*}{ Superficiais } & $\begin{array}{l}\text { 'Quebra muito galho', } \\
\text { 'Meio de socorro' }\end{array}$ & Economiza tempo, se faz negócios \\
\hline & 'Funciona como Bússola' & Auxilia na localização \\
\hline & 'É como um pássaro' & Proporciona liberdade \\
\hline
\end{tabular}

Fonte: Kraft e Nique (2002).

A perspectiva de Zaltman é importante para entender como as imagens avançam para o campo das representações sensoriais e emocionais, não se restringindo às manifestações racionais. Dessa forma, a ZMET se apresenta como importante técnica para mensurar as imagens de forma ampla e confiável. Por outro lado, sua operacionalização é complexa. A ZMET, além de uso de tecnologia para a formatação das metáforas, exige profissionais altamente especializados para dirigir todo o processo. Além disso, o custo e o tempo de mensuração das metáforas compromete muitos estudos que necessitem trabalhar com amostras maiores. Isso se reflete também na pouca quantidade de pesquisas feitas por outros autores que utilizam a técnica ZMET.

\section{Análise Comparativa entre as Três Técnicas}

A comparação dos resultados do procedimento de delimitação da Imagem Central de Produtos aqui proposto pela TCIP - Técnica de Configuração da Imagem de Produtos com os resultados obtidos através de outros procedimentos, já validados e amplamente adotados na pesquisa científica, confere validade ao procedimento proposto, nesse esforço de pesquisa.

O Quadro 6 apresenta sumariamente o resultado da delimitação dos sistemas central e periférico da Imagem do Telefone Celular, para uma representação de estudantes universitários de Administração, no Estado do Rio Grande do Sul, a partir dos três instrumentos abordados neste trabalho. 


\section{Quadro 6: Delimitação dos Sistemas Central e Periférico da Imagem do Telefone Celular através da TCIP, do EVOC e da ZMET}

\begin{tabular}{|c|c|c|c|}
\hline TCIP & $\begin{array}{c}\text { Atributos } \\
\text { encontrados e } \\
\text { organizados pela } \\
\text { TCIP }\end{array}$ & $\begin{array}{c}\text { Atributos } \\
\text { encontrados e } \\
\text { organizados pelo } \\
\text { EVOC }\end{array}$ & $\begin{array}{c}\text { Metáforas encontradas e } \\
\text { organizadas pela } \\
\text { ZMET } \\
\text { (por análise de conteúdo) }\end{array}$ \\
\hline \multirow{4}{*}{$\begin{array}{c}\text { Imagem Central } \\
\text { (TCIP) }\end{array}$} & Praticidade & Praticidade & Praticidade \\
\hline & Necessidade & Necessidade & Necessidade \\
\hline & Aparelho & Aparelho & Aparelho \\
\hline & Tecnologia & Tecnologia & Tecnologia \\
\hline \multirow{3}{*}{$\begin{array}{l}\text { Núcleo Central } \\
\text { (EVOC) }\end{array}$} & Utilidade & Utilidade & Utilidade \\
\hline & $\begin{array}{l}\text { Facilidade de } \\
\text { Comunicação }\end{array}$ & $\begin{array}{l}\text { Facilidade de } \\
\text { Comunicação }\end{array}$ & Facilidade de Comunicação \\
\hline & Comunicação & Comunicação & Comunicação \\
\hline \multirow{5}{*}{$\begin{array}{l}\text { Metáforas Profundas } \\
\text { (ZMET) }\end{array}$} & Agilidade & & Agilidade \\
\hline & & Comodidade & \\
\hline & & & Marca \\
\hline & & & Onipresença \\
\hline & & & Discrição \\
\hline \multirow{11}{*}{$\begin{array}{c}\text { Primeira e Segunda } \\
\text { Periferias } \\
\text { (TCIP) } \\
\text { Elementos Intermediários } \\
1 \text { e } 2 \\
\text { (EVOC) }\end{array}$} & & Agilidade & \\
\hline & Comodidade & & Comodidade \\
\hline & Marca & Marca & \\
\hline & Onipresença & Onipresença & \\
\hline & Discrição & Discrição & \\
\hline & Trabalho & Trabalho & Trabalho \\
\hline & Chatice & Chatice & \\
\hline & Conta & Conta & \\
\hline & Interação & & Interação \\
\hline & Segurança & & Segurança \\
\hline & & Liberdade & Liberdade \\
\hline \multirow{6}{*}{$\begin{array}{c}\text { Metáforas Temáticas } \\
\text { (ZMET) }\end{array}$} & & Status & Status \\
\hline & & Informação & \\
\hline & Serviço & & \\
\hline & & & Prazer \\
\hline & & & Alegria \\
\hline & & & Companheirismo \\
\hline \multirow{4}{*}{$\begin{array}{l}\text { Periferia } \\
\text { (TCIP) }\end{array}$} & Status & & \\
\hline & & Segurança & \\
\hline & & Serviço & \\
\hline & & Interação & \\
\hline \multirow{3}{*}{$\begin{array}{c}\text { Sistema Periférico } \\
\text { (EVOC) }\end{array}$} & Prazer & Prazer & \\
\hline & Alegria & Alegria & \\
\hline & Companheirismo & Companheirismo & \\
\hline \multirow{3}{*}{$\begin{array}{c}\text { Metáforas Superficiais } \\
\text { (ZMET) }\end{array}$} & Informação & & Informação \\
\hline & Liberdade & & Liberdade \\
\hline & Solução & Solução & Solução \\
\hline
\end{tabular}

Fonte: Coleta de Dados e Kraft e Nique (2002).

Dos oito atributos identificados como componentes da Imagem Central pela TCIP, apenas o atributo 'Agilidade' não está no Núcleo Central encontrado pelo EVOC, encontrando-se, porém, bem próximo a ele, na Imagem Intermediária 1. O atributo 'Comodidade' constitui outra diferença em relação ao resultado do EVOC, uma vez que a TCIP o coloca na Primeira Periferia, enquanto o EVOC o considerou como fazendo parte do Núcleo Central da Imagem. No entanto encontramos grande 
semelhança entre os dois tratamentos dispensados à mesma base de dados por essas duas técnicas. Temos sete coincidências para duas diferenças. Também com relação aos resultados da ZMET, identifica-se grande semelhança entre os atributos pertencentes à Imagem Central delineada pela TCIP com as metáforas profundas da ZMET, encontradas por Kraft e Nique (2002), após análise de conteúdo para equalização dos termos. Encontram-se oito coincidências, para três diferenças. Essa maior diferença na comparação com a técnica da ZMET pode ser em parte atribuída ao fato de se tratar de outro esforço de pesquisa, com outra base de dados, recolhida junto a outra amostra, em outro período. Esses resultados permitem encarar a (TCIP - Técnica de Configuração da Imagem de Produtos) como procedimento bastante válido para a descriminação entre os sistemas periférico e central das imagens de produto. Maiores avanços metodológicos devem, entretanto, ser feitos para a discriminação mais válida entre várias zonas do sistema periférico, pois ali encontramos maiores discordâncias entre os métodos testados.

Esses resultados representam um avanço no conjunto de métodos para o acesso às imagens que norteiam o comportamento de consumo, pois a TCIP é de aplicação mais fácil, rápida e econômica que os demais métodos existentes no momento.

\section{Teste de Confiabilidade do Procedimento de Designação da Imagem Central a partir da (TCIP - Técnica de Configuração da Imagem de Produtos)}

O Quadro 7 apresenta os resultados do teste reverso onde, para uma nova amostra do mesmo universo, os atributos da Imagem Central e da Imagem Periférica do Telefone Celular foram apresentados aos respondentes, verificando o índice de reconhecimento do TC que cada conjunto de atributos provocava.

\section{Quadro 7: Teste do Procedimento de Designação da Imagem Central}

\begin{tabular}{|l|c|c|c|c|}
\hline $\begin{array}{c}\text { Respostas } \\
\text { dadas pela amostra } \\
\text { aos estímulos em } \\
\text { cartões }\end{array}$ & $\begin{array}{c}\text { Estímulo 2 } \\
\text { Atributos formadores da } \\
\text { Imagem Central } \\
\text { identificada pela TCIP }\end{array}$ & $\%$ & $\begin{array}{c}\text { Estímulo 1 } \\
\text { Atributos formadores da } \\
\text { Imagem Periférica } \\
\text { identificada pela TCIP }\end{array}$ & $\%$ \\
\hline Tel. Celular & 22 & 70,97 & 0 & 0,00 \\
\hline Carro & & & 4 & 12,90 \\
\hline Computador & 4 & 12,90 & 3 & 9,68 \\
\hline Outros Produtos & 4 & 12,90 & 12 & 38,71 \\
\hline Serviço & 1 & 3,23 & 11 & 35,48 \\
\hline Não Resposta & & & 1 & 3,23 \\
\hline \multicolumn{1}{|c|}{ Total } & 31 & 100,0 & 31 & 100,0 \\
\hline
\end{tabular}

Fonte: Tratamento dos Dados. 
Os resultados apresentados no Quadro 7 mostram que, ante a apresentação do estímulo 2 (atributos que compõem a Imagem Central do TC), 22 dos 31 entrevistados $(70,97 \%)$, responderam que os atributos se referem ao TC, enquanto os demais sugeriram que fosse algum outro produto. Já com o estímulo 1 (atributos da imagem periférica do TC), ninguém conseguiu identificar o TC.

Os resultados deste experimento apontam a confiabilidade da TCIP - Técnica de Configuração da Imagem de Produtos para a determinação dos Sistemas Central e Periférico da Imagem de um Produto.

\section{Considerações Finais}

Os resultados da análise realizada nesse trabalho comprovam que o procedimento de Identificação e Organização dos Atributos da Imagem da TCIP, Técnica de Configuração da Imagem de Produtos, mostrou-se válido e confiável, nesse esforço de pesquisa.

A TCIP constitui uma ferramenta útil, simples e econômica para melhor entender como o público alvo vê determinado produto e como organiza a sua imagem na mente. O que diferencia a TCIP dos métodos até agora desenvolvidos para a mensuração da imagem de produtos é sua facilidade de aplicação, associada a um grande poder de configuração da imagem que determinado grupo de consumidores formou de um produto dado.

As principais informações que ela fornece, em relação ao procedimento específico aqui testado, servem tanto para orientar esforços de $\mathrm{P} \& \mathrm{D}$, para a constante atualização da presença desse produto no mercado, quanto para fundamentar as decisões sobre seu posicionamento em relação à concorrência, através da comunicação, da geração de benefícios e de argumentos de venda.

A aplicação da TCIP mostra quais idéias (atributos) estão associadas à imagem do produto estudado, para determinado público. Isto revela suas opiniões, expectativas e preferências, também suas queixas, percepções negativas e decepções. Isso indica quais características do produto manter, quais extinguir ou modificar e quais melhorar, para que a imagem fique cada vez mais positiva.

A posição dessas idéias (atributos) em diferentes áreas (na Imagem Central ou na Periférica) informa sobre a qualidade da ligação dessas idéias com o conceito do produto, dando uma noção do trabalho necessário para manter ou afastar essas idéias, visando à geração de melhor imagem para o produto. Uma 
idéia positiva, atrelada à Imagem Central do produto, indica oportunidade fácil de promessa básica (argumento de venda), se a realidade do produto for capaz de sustentar essa crença. Uma idéia negativa, na Imagem Central, indica problema grave, que vai demandar tempo e investimento para ser resolvido, uma vez que sua ligação com o conceito do produto é muito forte. Uma idéia altamente positiva, disposta em área periférica da imagem, indica que um trabalho de aproximação dessa idéia da Imagem Central é possível, trazendo para isso uma melhoria geral na imagem do produto. Essa idéia poderá ser utilizada como substituta de uma idéia negativa na Imagem Central, quando devidamente sustentada, tanto pela realidade do produto, quanto pela sua comunicação, durante o tempo suficiente para que a troca seja feita, na mente dos consumidores. Esse trabalho exigirá frequiência, constância e vivacidade na comunicação e em todos os contatos com o produto que esse público tiver, durante o tempo necessário, para que as modificações da imagem se processem. Já uma imagem negativa, em área periférica da imagem, representa um trabalho mais fácil de desligamento, desde que esse trabalho não seja menosprezado ou negligenciado. Reforçar esse atributo, por qualquer experiência de contato do público com a idéia do produto, pode trazê-la para a sua Imagem Central. É sinal de alerta para o produtor.

A organização que utilizar a TCIP regularmente, para analisar a imagem de seus produtos junto aos seus nichos específicos de consumo, contará com forte auxiliar na efetiva administração de sua oferta ao mercado.

Apesar da contribuição desse esforço de pesquisa para a validação de um procedimento para a configuração da imagem de produtos, são necessárias novas pesquisas, para o aperfeiçoamento do método em desenvolvimento.

\section{Artigo recebido em 30.10.2004. Aprovado em 06.06.2005.}

\section{ReferênCias Bibliográficas}

Abric, J. C. (1984).

A theoretical and experimental approach to the study of social representations in a situation of interaction. In R. Farr \& S. Moscovici (Eds.). Social Representations (pp. 169-183). Cambridge: University Press.
Abric, J. C. (1993).

Central system, peripheral system: their functions and roles in the dynamics of social representations. Papers on Social Representations, 2(2), 75-78. 
Akhter, S. H.,

Andrews, J. C., \&

Durvasula, S. (1994).

The influence of retail store environment on brand-related judgments. Jounal of Retailing and Consumer Service, 1(2), 67-76.

Ayrosa, E. T. (2002).

Consumer attitudes towards products from non-stereotypical countries: What happens when country of origin information doesn't ring a bell? Anais do Encontro Nacional dos Programas de Pós-Graduação em Administração, Salvador, BA, Brasil, 26.

Barich, H., \&

Kotler, P. (1991).

A framework for marketing image management. Sloan Management Review, 32(2), 97-104.

Churchill, G. A. (1979).

A paradigm for developing better measures of marketing constructs. Journal of Marketing Research, 16(1), 64-73.

Dichter, E. (1985).

What's in an image. Journal of Consumer Marketing, 2(1), 75-81.

Dobni, D., \&

Zinkhan, G. M. (1990).

In search of grand image: a foundation analysis. Advances in Consumer Research, 17(1), 110-119.

Flick, U. (1992).

Combining methods-lack of methodology: discussion of Sotirakopoulou \& Breakwell. Ongoing Production on Social Representation, 1(1), 43-48.
Gentner, D. (1983).

Mental models. Hillsdale: Lawrence Erlbaum Associate.

Goleman, D. (1995).

Inteligência emocional: a teoria revolucionária que redefine o que é ser inteligente. Rio de Janeiro: Objetiva.

Kraft, S., \&

Nique, W. M. (2002).

Desvendando o consumidor através das metáforas: uma aplicação da zaltman metaphor elicitation technique (ZMET). Anais do Encontro Nacional dos Programas de Pós-Graduação em Administração, Salvador, BA, Brasil, 26.

Ledoux, J. (2001).

O cérebro emocional: os misteriosos alicerces da vida emocional. Rio de Janeiro: Objetiva.

Levy, S. J. (1981).

Interpreting consumer mythology: a structural approach to consumer behavior. Journal of Marketing, 45(3), 49-61.

Lindquist, J. D. (1975).

Meaning of image: a survey of empirical and hypothetical evidence. Journal of Retailing, 50(4), 29-38.

Lockhart, R. S. (2001).

Memory retrieval. In International Encyclopedia of the Social \& Behavioral Science (pp. 9613-9618). London: Elsevier.

Logie, R. H., \& Sala, D. (2001).

Psychology of working memory. In: International Encyclopedia of the Social \& Behavioral Science (pp. 16587-16593). London: Elsevier. 
Malhotra, N. K. (2001).

Pesquisa de marketing: uma orientação aplicada. (3a. ed.). Porto Alegre: Bookman.

Martineau, P. (1958).

The personality of the retail store. Harvard Business Review, 36(1). 4755.

Meyers-Levy, J., \&

Tybout, A. M. (1989).

Schema congruity as a basis for product evaluation. Journal of Consumer Research, 16(1), 39-54.

Moscovici, S. (2000).

Social representation: explorations in social psychology. Cambridge: Polity Press.

Parameswaran, R., \&

Pisharodi, R. M. (1994).

Facets of country of origin image: an empirical assessment. Journal of Advertising, 23(1) 43-56.

Poiesz, T. B. C. (1989).

The image concept: its place in consumer psychology. Journal of Economic Psychology, 10(4), 457-472.

Reynolds, T. J., \&

Gutman, J. (1984).

Advertising is image management. Journal of Advertising, 24(1), 27-37.
Sá, C. P. de (1996).

Sobre o núcleo central das representações sociais. Petrópolis, RJ: Vozes.

Schacter, D. L. (1996).

Searching for memory: the brain, the mind, and the past. New York: BasicBooks.

Stern, B.,

Zinkhan, G. M., \&

Jaju, A. (2001).

Marketing images: construct definition, measurement issue, and theory development. Marketing Theory, 1(2), 201-224.

Sternberg, R. J. (2000).

Psicologia cognitiva. Porto Alegre: Artes Médicas Sul.

Vergès, P. (1992).

L'évocation de l'argent: une méthode pour la definition du noyau central dune representation. Bulletin de Psychologie, 45(405), 203-209.

Zaltman, G., \&

Coulter, R. H. (1995).

Seeing the voice of the customer: metphor-based advertising research. Journal of Advertising Research, 35(4), 35-51. 
